\title{
Knowledge, Attitude and Practice of Birth Preparedness and Complication Readiness Amongst Pregnant Women in Eti-osa Lga, Lagos
}

\author{
Mbonu, Ebere Ogonna \\ Department of Community Health and Primary Care, College of Medicine, University of Lagos, Nigeria
}

Copyright $\bigcirc 2018$ by authors, all rights reserved. Authors agree that this article remains permanently open access under the terms of the Creative Commons Attribution License 4.0 International License

\begin{abstract}
Background: Maternal mortality still remains a major challenge in developing countries. In sub-Saharan Africa, one out of every sixteen women dies of pregnancy-related causes. Birth preparedness and complication readiness is the process of planning for normal birth and anticipating the actions needed in case of an emergency. This is a study to assess the knowledge, attitude and practice of birth preparedness and complication readiness. Methodology: This is a descriptive cross-sectional study to assess the knowledge, attitude and practice of birth preparedness and complication readiness among antenatal care attendees in Eti-Osa local government area of Lagos State. A systematic sampling technique was used to select the respondents.The data used for this study were collected from pregnant women attending antenatal care in Six Primary Health Care centers in Eti-Osa local government area of Lagos State, using a structured pretested English language, interviewer-administered questionnaire. Results: The mean age of the respondents was 28.9 years, with standard deviation of 5.3 years. The proportion of respondents who have been prepared for birth and for its possible complication was $124(33.4 \%)$. A higher proportion of the married women $212(72.6 \%)$ were better prepared for birth and ready for its possible complication. 120 (83.9\%) of pregnant women who had attended tertiary education were prepared for birth and for its complications $(p=0.001)$ Conclusion: Few pregnant women had made adequate arrangements in anticipation for a safe normal delivery.
\end{abstract}

Keywords Birth Prepared Complication Ready, Pregnant Women, Antenatal Care, and Primary Health Care

\section{Introduction}

Pregnancy is the physical condition of a woman carrying unborn offspring inside her body, from fertilization to birth. Child birth is the processes of having a baby emerge from the womb. Under normal conditions, pregnancy and child birth are not a disease but a physiological process. There is, therefore, no need for any woman to die as a result of pregnancy or child birth. In developing countries of the world, many women face increased risk of morbidity from pregnancy and child birth [1].

Birth preparedness and complication readiness is the process of planning for normal birth and anticipating the actions needed in case of an emergency [2]. Responsibility for birth preparedness is shared among all the stakeholders of safe motherhood: policymakers, facility managers, providers, communities, families, and women, because a coordinated effort is needed to reduce the delays that contribute to maternal and newborn deaths [2]. Birth preparedness covers all aspects of pregnancy and child birth, including preconception care, antenatal care, and medical problems during pregnancy, disorder that might affect the unborn baby, complications arising during pregnancy, the induction of labor, and the care of the mother and child during childbirth [3]. It aids the pregnant woman in the identification of the risk factors that can lead to complications in pregnancy. These risk factors include: hemorrhage, infection, anemia, smoking, hypertension, poor diet, diabetes, etc. It involves adequate and proper planning for the physical, psychological, financial and emotional aspect that can affect the outcome of pregnancy. Despite the great potential of birth preparedness for reducing the maternal and newborn deaths, the success of this strategy is not well known in most of Sub-Sahara Africa [4].

\section{Statement of the Problem}

Maternal mortality remains a major public health challenge in the developing countries, and the little progress made towards the achievement of millennium 
development goals, especially the goal of achieving three-quarter reduction in maternal mortality ratio by 2015 can essentially be attributed to the little achievements of low and middle income countries in this regard. A major strategy that can reduce the maternal mortality ratio is to making a birth plan or birth preparedness and complication awareness [4].

Lack of advance planning for accessing the services of a skilled birth attendant for normal births, and inadequate preparation for rapid intervention in the event of obstetric complications, are well documented factors contributing to delay in receiving skilled obstetric care. Globally, about 289,000 mothers die each year because of problems related to pregnancy and child birth. About $95 \%$ of these cases occur in developing countries, Sub-Saharan Africa (56\%) and Southern Asia (29\%) accounts for $85 \%$ of the global burden of maternal death [5]. With this disparity, the maternal mortality rate in developing countries is more than 15 times higher than in the developing regions [5]. While almost all developed countries have achieved the desired three-quarter reduction of maternal mortality by 2015 , many of developing countries are still struggling. However, most of the resource limited countries in Sub-Saharan Africa have shown the slowest progress, with an average annual rate of decline of $2.6 \%$ [6].

Nigeria is one of the Sub-Saharan African countries with high maternal mortality ratio (MMR). The MMR in the Nigerian Demographic and Health Survey (NDHS) in 2015 was 560 per 100,000 live births, which had shown a slightly significant decline compared to 740 and 950 per 100,000 live births in NDHS surveys in 2005 and 2000, respectively [7]. As a result, improving maternal health status so as to achieve the intended target is among the top priority areas of the country.

\section{Justification and Rationale of the Study}

Maternal mortality is one of the key indices of the health state and quality of health care of a society. The public health burden of maternal mortality is huge, hence improving maternal health has received recognition at the global level as evidenced by its inclusion in millennium developmental goals. Owing to pregnancy- related complications, more than half a million women die each year worldwide [8]. Ninety-nine percent of maternal deaths occur in the developing world, and most of these deaths are preventable [9]. The chances of dying from maternal complications are 1 in 16 in developing countries, compared to 1 in 2800 in developed countries [10]. Each year, more than 50 million women give birth at home and without the help of a trained professional [11]. For every woman who dies during childbirth, another 30 women suffer injury, infection or complications [9].

Birth preparedness and complication readiness is a strategy to promote utilization of skilled maternal and neonatal care timely, based on the theory that preparing for childbirth and being ready for complications reduces delays in obtaining this care [12]. In a skilled care approach, birth preparedness includes identifying a skilled provider and making the necessary plans to receive skilled care for all births [13].Complication readiness (emergency funds, transport, blood donor and designated decision maker) receive greater emphasis in emergency obstetric care programs.

Birth preparedness and complication readiness has been globally endorsed as an essential component of safe motherhood programs to reduce delays for care [13].

The research seeks to assess the knowledge, attitude and practice of birth preparedness and complication readiness and also factors that are associated with it. The findings from this study will provide information for informed public health actions targeted towards reduction of maternal mortality. It will also contribute to research in area of improvement of maternal health.

\section{Study Objective}

The general objective of this present research is to assess the knowledge, attitude and practice of Birth preparedness and complication readiness among antenatal care attendees in Eti-Osa Local Government Area of Lagos State.

The study has the following specific objectives:

1. To assess the Knowledge of Birth preparedness and complication readiness among antenatal care attendees in Eti-Osa Local Government Area of Lagos State.

2. To determine the attitude of pregnant women attending antenatal care in Eti-osa LGA to birth preparedness and complication readiness.

3. To identify the factors associated with birth preparedness and complication readiness among antenatal care attendees in Eti-Osa Local Government Area of Lagos State.

\section{Materials and Method}

This is a cross-sectional descriptive study, aimed at assessing the knowledge, attitude and practice of birth preparedness and complication readiness among antenatal clinic attendees in Eti-Osa Local Government Area of Lagos State.

The study was conducted amongst pregnant women attending primary health care in Eti-Osa local government area.

Only pregnant women, permanent residents, who attend ante-natal care in primary health care in Eti-Osal local government area.

Those who failed to give consent and were temporary residents in the study area were excluded. These criteria were applied to ensure a uniform selection of study participants.

The minimum sample size was determined [14] by using the Cochrane formula for a population greater than 10,000. 


$$
\mathrm{n}=\mathrm{Z}{ }^{2} \mathrm{pq} / \mathrm{d}^{2}
$$

Where $\mathrm{n}=$ Minimum sample size required

$\mathrm{Z}=$ level of statistical significance at $95 \%$ confidence level i.e. 1.96

$\mathrm{p}=$ Awareness of birth preparedness and complication readiness (A study carried out in Ethiopia)

$\mathrm{d}=$ Acceptable margin of sampling error 0.05

$\mathrm{q}=1-\mathrm{p}$

Therefore, by considering:

$\mathrm{Z}=1.96$

$\mathrm{P}=70.6 \%$ to decimal $=0.706$

$\mathrm{q}=1-0.706$

The minimum number of patients included in this study resulted as

$$
\begin{aligned}
& =0.294 \\
& =\frac{1.96 \times 0.706 \times 0.294}{0.05^{2}} \\
& =\frac{3.841 \times 0.706 \times 0.294}{0.0025} \\
& =318.95
\end{aligned}
$$

If $10 \%$ of the total number of respondents gave a non-valid response, then the minimum number of patients becomes:

$$
\begin{aligned}
& n(100 \%-10 \%) \\
& \begin{aligned}
n & =\frac{319}{0.90} \\
& =354.4 \\
& =360 \text { to nearest whole number }
\end{aligned}
\end{aligned}
$$

Finally, the number of subjects of in this study was of 360 pregnant women.

\section{Sampling Technique}

A total of 360 pregnant women who attended antenatal clinic in the PHC were recruited for the study. A systematic sampling technique was used for selection of the subjects based on the monthly clinic attendance and using the antenatal care register obtained from the health care workers in each primary health care center. With a sampling interval of 2 (i.e., 120/60), 1 in every 2 antenatal care clients was selected until the required sample size was met. The starting point for selection was determined by picking a random number from the clinic register, between 1 and 2. Subsequent respondents were identified by adding the sampling interval to the preceding respondents' serial number on the ANC register until the required sample size was met.

After selecting a random starting point, the respondents in each primary health care center was selected untill the desired sample size in each PHC was reached. The respondents were selected proportionally to client caseload per level of facility.

\section{Data Collection Tool}

The data in this study were collected using a structured pretested English language interviewer-administered questionnaire. A standard tool adapted from the safe motherhood questionnaire developed by maternal and neonatal health program of John Hopkins Program for International Education in Gynecology and Obstetrics (JHPIEGO) the affiliate of John Hopkins University [15]. The questionnaire was divided into four sections, namely: socio-demographics, knowledge, attitude and practice of birth preparedness and complication readiness among antenatal care Prior to the actual study, the questionnaire was tested among pregnant women in Isolo LGA. Feedback from the pre-test was used to make appropriate corrections in the questionnaire

\section{Data Collection and Analysis}

On the day of data collection, each pregnant woman in the selected PHC center was first informed of the reason and nature of the study. They were assured that information provided will be treated with strict confidentiality. All completed questionnaire was collected and appropriately coded immediately after. Prior to data analysis, the information was collected using Microsoft excel office software. It was imported into Statistical Package for Social Sciences (SPSS) version 21 software. The analysis was done using SPSS. Quantitative variables were expressed as means, standard deviation and qualitative variables as frequencies and percentages and test of association carried out using Chi-square and Fishers Exact with level of significance set as $\mathrm{P}<0.05$.

Knowledge of Birth Preparedness and Complication Readiness: A total of six questions was given to the respondents to assess their level of knowledge on Birth Preparedness and Complication Readiness. The questions were collated and graded as follows: those who scored between 3-6 marks (above 50\%) were said to have good knowledge, while those who scored between 0-2 marks (below 50\%) were said to have a poor knowledge of birth preparedness and complication readiness [16].

Attitude towards Birth Preparedness and Complication Readiness: A total of seven questions relating to the respondents attitude to birth preparedness and complication readiness. Each response was graded according to Likert scale. Each item score between 1 to 5 points. The options were:5 points for 'Strongly agree', 4 points for 'agree, 3 points for 'disagree' 2 points for 'strongly disagree' 1 point for 'undecided'. The answers collated were then converted to 1 (Agree and Strongly agree) and 0 (Undecided, Strongly disagree and Disagree). Those who scored between 7-14 marks (50\% and above) were considered as having a positive attitude while those who scored between 0-6 marks (50\% and below) were considered as negative attitude towards birth preparedness and complication readiness [16].

Practice of Birth Preparedness and Complication Readiness: A total of five questions relating to the 
respondents practice of birth preparedness and complication readiness (BPCR). A pregnant woman was considered "prepared" for birth and its complications if she reported to follow at least 3 of the 5 basic components of BPCR (that scores between 1-5points) while those who scored between 0-3 points where considered as "not prepared" for birth and its complications [16,17].

\section{Ethical Considerations}

Ethical approval for this study was obtained from the Ethical and Research Committee of Lagos University Teaching Hospital .Institutional ethical clearance was obtained and assent granted by the Executive Chairman of the LGA, Medical Officer of Health and Officer In-Charge of the Primary Health Care Centers. The respondents were assured of their freedom to participate and also to withdraw from the study at any time they wished. Privacy and confidentiality of the respondents information's was respected during and after the interview. Data were kept secure.

\section{Results}

The result of 360 subjects, representing the responses of all the pregnant women in the study as presented in Tables $1-8$.

Table 1. Socio-demographic characteristics of respondents $(\mathrm{N}=360)$

\begin{tabular}{|c|c|c|}
\hline Socio-demographic & No of Cases & Percentage of total of cases studied \\
\hline \multicolumn{3}{|l|}{ Age (years) } \\
\hline$<21$ & 25 & 6.9 \\
\hline $21-25$ & 57 & 15.8 \\
\hline $26-30$ & 143 & 39.7 \\
\hline $31-35$ & 112 & 31.2 \\
\hline $36-40$ & 12 & 3.3 \\
\hline$>40$ & 11 & 3.1 \\
\hline \multicolumn{3}{|l|}{ Religion } \\
\hline Christian & 149 & 41.4 \\
\hline Islam & 199 & 55.3 \\
\hline Others* & 12 & 3.3 \\
\hline \multicolumn{3}{|l|}{ Ethniciy } \\
\hline Ibo & 118 & 32.8 \\
\hline Yoruba & 194 & 53.9 \\
\hline Hausa & 30 & 8.3 \\
\hline Others** & 18 & 5.0 \\
\hline \multicolumn{3}{|l|}{ Marital status } \\
\hline Single & 47 & 13.1 \\
\hline Married & 292 & 81.1 \\
\hline Separated/ Divorced & 19 & 5.2 \\
\hline Widowed & 2 & 0.6 \\
\hline \multicolumn{3}{|l|}{ Education } \\
\hline Primary & 101 & 28.1 \\
\hline Secondary & 99 & 27.5 \\
\hline Tertiary & 143 & 39.7 \\
\hline None & 17 & 4.7 \\
\hline \multicolumn{3}{|l|}{ Occupation } \\
\hline Skilled & 117 & 32.5 \\
\hline Semi-skilled & 98 & 27.2 \\
\hline Unskilled & 123 & 34.2 \\
\hline Don’t know & 22 & 6.1 \\
\hline Socio-demographic & No of Cases & Percentage of total of cases studied \\
\hline \multicolumn{3}{|c|}{ Number of weeks pregnant } \\
\hline $1-12$ weeks & 63 & 17.5 \\
\hline 13-24 weeks & 188 & 52.3 \\
\hline $25-40$ weeks & 109 & 30.2 \\
\hline \multicolumn{3}{|l|}{ History of stillbirth } \\
\hline Yes & 50 & 13.9 \\
\hline No & 310 & 86.1 \\
\hline \multicolumn{3}{|c|}{ Pregnant in the past one year } \\
\hline No & 103 & 28.6 \\
\hline Yes & 257 & 71.4 \\
\hline
\end{tabular}




\section{$\operatorname{Parity}(\mathbf{n}=\mathbf{2 5 7})$}

$\begin{array}{lll}\text { Less than } 3 & 83 & 32.3\end{array}$

3 or more

174

67.7

The mean age group of the respondents is $28.9 \pm 5.3$ and majority of the respondents were between the ages $26-30$ years.

Table 2. knowledge of birth preparedness and complication readiness for study respondents $(\mathrm{N}=360)$

\begin{tabular}{|c|c|c|}
\hline knowledge of birth preparedness and complication readiness & No of Cases & $\begin{array}{l}\text { Percentage of total } \\
\text { of cases studied }\end{array}$ \\
\hline \multicolumn{3}{|l|}{ Heard of birth preparedness and complication readiness } \\
\hline Yes & 232 & 64.4 \\
\hline No & 128 & 35.6 \\
\hline \multicolumn{3}{|l|}{ Sources of information $(n=\mathbf{2 3 2})$} \\
\hline Media(Television, radio, etc) & 153 & 65.9 \\
\hline Health worker(Doctor, Nurse,etc) & 227 & 97.8 \\
\hline Family & 61 & 26.3 \\
\hline Friends & 68 & 29.3 \\
\hline Internet & 2 & 0.9 \\
\hline \multicolumn{3}{|l|}{ Total Number of times to attend ANC $(n=360)$} \\
\hline One & 12 & 3.3 \\
\hline Two & 72 & 20.0 \\
\hline Three & 62 & 17.2 \\
\hline Four or more & 185 & 51.4 \\
\hline \multicolumn{3}{|l|}{ Danger signs during pregnancy } \\
\hline Severe vaginal bleeding & 312 & 86.7 \\
\hline Severe headache & 291 & 80.8 \\
\hline Blurred vision & 143 & 39.7 \\
\hline Convulsion & 149 & 41.4 \\
\hline Swollen hand and face & 146 & 40.6 \\
\hline High fever & 9 & 2.5 \\
\hline Loss of consciousness & 65 & 18.1 \\
\hline Severe abdominal pain & 17 & 4.7 \\
\hline Acceralated or reduced fetal movement & 26 & 7.2 \\
\hline \multicolumn{3}{|l|}{ Danger signs during labour and childbirth } \\
\hline Severe vaginal bleeding & 269 & 74.7 \\
\hline Severe headache & 229 & 63.6 \\
\hline Convulsion & 141 & 39.2 \\
\hline knowledge of birth preparedness and complication readiness & No of Cases & $\begin{array}{l}\text { Percentage of } \\
\text { total of cases } \\
\text { studied }\end{array}$ \\
\hline High fever & 71 & 19.7 \\
\hline Loss of consciousness & 140 & 38.9 \\
\hline Labour lasting for more than 12 hours & 71 & 19.7 \\
\hline \multicolumn{3}{|l|}{ Danger signs during post-partum } \\
\hline Severe bleeding & 209 & 58.1 \\
\hline Severe headache & 200 & 55.6 \\
\hline Blurred vision & 131 & 36.4 \\
\hline Convulsion & 131 & 36.4 \\
\hline Swollen hands and face & 122 & 33.9 \\
\hline High fever & 119 & 30.9 \\
\hline Foul smelling vaginal discharge & 122 & 33.9 \\
\hline Loss of consciousness & 29 & 8.1 \\
\hline
\end{tabular}

A great number of respondents $232(64.4 \%)$ have heard about birth preparedness and complication readiness, while the remaining 128 (35.6\%) have not heard about it. 
Table 3. Knowledge of birth preparedness and complication readiness for study respondents $(\mathrm{N}=360)$ continues

\begin{tabular}{|c|c|c|}
\hline Knowledge of Birth Preparedness and complication readiness & No of Cases & Percentage of total of cases studied \\
\hline Attending antenatal care services $(n=360)$ & 347 & 96.4 \\
\hline Identifying skilled provider & 229 & 63.6 \\
\hline Identifying mode of transport & 220 & 61.1 \\
\hline Saving money & 279 & 77.5 \\
\hline Identifying company & 141 & 39.2 \\
\hline \multicolumn{3}{|l|}{ Knowledge of death from danger signs $(n=360)$} \\
\hline During pregnancy Yes & 229 & 63.6 \\
\hline No & 59 & 16.4 \\
\hline Don’t know & 72 & 20.0 \\
\hline \multicolumn{3}{|l|}{ During labour and delivery } \\
\hline Yes & 217 & 60.3 \\
\hline No & 58 & 16.1 \\
\hline Don’t know & 85 & 23.6 \\
\hline \multicolumn{3}{|l|}{ During post-partum } \\
\hline Yes & 229 & 63.6 \\
\hline No & 59 & 16.4 \\
\hline \multicolumn{3}{|l|}{ Knowledge of availability of community support systems $(n=360)$} \\
\hline \multicolumn{3}{|l|}{ Financial support system } \\
\hline Yes & 16 & 4.4 \\
\hline No & 344 & 95.6 \\
\hline \multicolumn{3}{|l|}{ Transport system } \\
\hline Yes & 29 & 8.1 \\
\hline No & 331 & 91.9 \\
\hline \multicolumn{3}{|l|}{ Blood donor system } \\
\hline Yes & 3 & 0.8 \\
\hline No & 357 & 99.2 \\
\hline
\end{tabular}

*Multiple responses allowed

Knowledge of birth preparedness and complication readiness was considered, based on the components of the birth preparedness and complication readiness concept. This means, those who knew the components as a way of preparing for birth and ready for the complications.

Table 4. Level of Knowledge towards birth birth preparedness and complication readiness $(\mathrm{N}=360)$

\begin{tabular}{ccc}
\hline Level of knowledge towards dangers signs of pregnancy & No of Cases & $\begin{array}{c}\text { Percentage of total of } \\
\text { cases studied }\end{array}$ \\
\hline Poor (0-49\%) & 261 & 72.5 \\
Good (50-100\%) & 99 & 27.5 \\
Level of knowledge towards birth preparedness and complication \\
$\begin{array}{c}\text { readiness } \\
\text { Poor (0-49\%) } \\
\text { Good (50-100\%) }\end{array}$
\end{tabular}

A total of $229(63.6 \%)$ respondent have a good knowledge of birth preparedness and complication readiness while 128 $(35.6 \%)$ of the respondents have a poor knowledge of birth preparedness and complication readiness. 

Readiness Amongst Pregnant Women in Eti-osa Lga, Lagos

Table 5. Attitude towards birth preparedness and complication readiness

\begin{tabular}{|c|c|c|c|c|c|}
\hline ATTITUDE STATEMENT & 1 & 2 & 3 & 4 & 5 \\
\hline $\begin{array}{c}\text { Seek medical help if she noticed any } \\
\text { danger signs during pregnancy }\end{array}$ & $298(82.7)$ & $41(11.4)$ & $5(1.4)$ & $11(3.1)$ & $5(1.4)$ \\
\hline \multicolumn{6}{|l|}{$\begin{array}{l}\text { Prepared for birth and its complications } \\
\text { by doing the following: }\end{array}$} \\
\hline Attend ANC & $269(74.7)$ & $1(0.3)$ & $10(2.7)$ & - & $80(22.3)$ \\
\hline Identify a skilled provider & $342(95.0)$ & $9(2.5)$ & $1(0.3)$ & - & $8(2.2)$ \\
\hline Identify mode of transport & $218(60.6)$ & $2(0.5)$ & $40(11.2)$ & $2(0.5)$ & $98(27.2)$ \\
\hline Identify company & $191(53.1)$ & $69(19.2)$ & - & - & $100(27.7$ \\
\hline Save money & $338(94.0$ & $8(2.2)$ & $4(1.1)$ & $1(0.3)$ & $9(2.5)$ \\
\hline Identify blood donor & 151(41.9) & $9(2.5)$ & $70(19.4)$ & $90(25.1$ & $40(11.1)$ \\
\hline
\end{tabular}

1- Strongly Agree, 2-Agree, 3-Strongly Disagree, 4-Disagree, 5-Undecide

Data presented on this table are number of subjects (n) and proportions (\%) of individual and their attitude towards birth preparedness and complication readiness.

Table 6. Attitude score TOWARDS birth preparedness and complication readiness RESPONDENTS $(\mathrm{n}=360)$

\begin{tabular}{ccc}
\hline Attitude & No of Cases & Percentage of total of cases studied \\
\hline Positive $(<50)$ & 271 & 75.3 \\
Negative $(>50)$ & 89 & 24.7 \\
\hline
\end{tabular}

Majority of the respondents 271 (75.3\%) of the respondents in this study, showed a positive attitude towards birth preparedness and complication readiness.

Table 7. Frequency Distribution of respondents by number of antenatal visits during pregnancy

\begin{tabular}{|c|c|c|}
\hline Total number times for antenatal care visits during pregnancy & No of Cases & $\begin{array}{c}\text { Percentage of total of } \\
\text { cases studied }\end{array}$ \\
\hline ONE & 8 & 2.2 \\
\hline TWO & 10 & 3.0 \\
\hline THREE & 187 & 51.9 \\
\hline FOUR OR MORE & 143 & 39.7 \\
\hline \multicolumn{3}{|l|}{ Means of transportation during delivery } \\
\hline Private care & 69 & 19.2 \\
\hline Taxi/bus & 134 & 37.2 \\
\hline Motorbike & 84 & 23.3 \\
\hline Boat & 12 & 3.3 \\
\hline On foot & 10 & 2.8 \\
\hline Tricycle & 51 & 14.2 \\
\hline \multicolumn{3}{|l|}{ Time of first ANC registration/visit } \\
\hline First trimester & 126 & 35.0 \\
\hline Second trimester & 162 & 45.0 \\
\hline Third trimester & 61 & 16.9 \\
\hline \multicolumn{3}{|l|}{ Practice of BPCR } \\
\hline Identified skilled provider & 159 & 34.2 \\
\hline Saved money for childbirth( & 286 & 79.4 \\
\hline Arranged for transport to place of childbirth & 152 & 42.2 \\
\hline Identified blood donor & 43 & 11.9 \\
\hline \multicolumn{3}{|l|}{ Practice of Birth preparedness and complication readiness } \\
\hline Prepared $(>50)$ & 124 & 34.4 \\
\hline Not prepared $(<50)$ & 236 & 65.6 \\
\hline
\end{tabular}


Data presented on this table, shows the percentage of cases who have made adequate preparations for child birth.

Table 8. Association of socio-demographic and obstetric factors of respondents with preparation for birth and its complication

\begin{tabular}{|c|c|c|c|c|}
\hline \multirow[t]{2}{*}{ VARIABLE } & \multicolumn{2}{|c|}{$\begin{array}{l}\text { PRACTICE OF BIRTH PREPAREDNESS AND COMPLICATION } \\
\text { READINESS }\end{array}$} & \multirow[t]{2}{*}{$\mathbf{X}^{2}$} & \multirow[t]{2}{*}{ P-VALUE } \\
\hline & Not prepared $(\%)$ & Prepared (\%) & & \\
\hline \multicolumn{5}{|l|}{ Age(years) } \\
\hline$<21$ & $14(56)$ & $11(44)$ & 27.193 & $0.176^{\mathrm{F}}$ \\
\hline $21-25$ & $40(70.1)$ & $17(29.8)$ & & \\
\hline $26-30$ & $40(36.8)$ & $103(63.2)$ & & \\
\hline $31-35$ & $41(28.0)$ & $71(72.0)$ & & \\
\hline $36-40$ & $1(8.3)$ & $11(91.7)$ & & \\
\hline$>40$ & $0(0.0)$ & $11(100.0)$ & & \\
\hline \multicolumn{5}{|l|}{ Religion } \\
\hline Christian & $60(40.2)$ & $89(59.7)$ & 22.907 & 0.0721 \\
\hline Islam & $84(42.2)$ & $115(57.7)$ & & \\
\hline Others & $7(58.3)$ & $5(41.6)$ & & \\
\hline \multicolumn{5}{|l|}{ Ethnicity } \\
\hline Ibo & $43(36.4)$ & $75(63.6)$ & 23.861 & 0.0756 \\
\hline Yoruba & $71(36.6)$ & $123(63.4)$ & & \\
\hline Hausa & $17(56.7)$ & $13(43.3)$ & & \\
\hline Others & $13(72.2)$ & $5(27.8)$ & & \\
\hline \multicolumn{5}{|l|}{ Marital status } \\
\hline Single & $30(63.8)$ & $17(36.2)$ & 60.511 & $0.000^{\mathrm{F}^{*}}$ \\
\hline Married & $80(27.4)$ & $212(72.6)$ & & \\
\hline Separated/divorced & $12(63.2)$ & $7(36.8)$ & & \\
\hline Widowed & $2(100.0)$ & $0(0.0)$ & & \\
\hline \multicolumn{5}{|l|}{ Education } \\
\hline Primary & $77(76.2)$ & $24(23.8)$ & 117.71 & $0.0001^{*}$ \\
\hline Secondary & $77(77.8)$ & $22(22.2)$ & & \\
\hline Tertiary & $23(16.1)$ & $120(83.9)$ & & \\
\hline None & $7(41.2)$ & $10(58.8)$ & & \\
\hline \multicolumn{5}{|l|}{ Occupation } \\
\hline Skilled & $23(19.7)$ & $94(80.3)$ & 54.696 & 0.056 \\
\hline Semi-skilled & $63(64.3)$ & $35(35.7)$ & & \\
\hline Unskilled & $31(25.2)$ & $92(74.8)$ & & \\
\hline None & $7(31.8)$ & $15(68.2)$ & & \\
\hline \multicolumn{5}{|l|}{ History of stillbirth } \\
\hline Yes & $6(12.0)$ & $44(88.0)$ & 12.954 & $0.0001^{*}$ \\
\hline No & $118(38.1)$ & 192(61.9) & & \\
\hline \multicolumn{5}{|l|}{ Parity } \\
\hline Less than 3 & $54(65.1)$ & $29(34.9)$ & 34.088 & $0.0001^{*}$ \\
\hline 3 or more & $59(33.9)$ & $115(66.1)$ & & \\
\hline
\end{tabular}

$\mathrm{F}=$ Fishers Exact

$\mathrm{X}^{2}$ chi-square

* Statistically significant 
There is statistically significant association $(\mathrm{p}<0.05)$ between the respondents marital status, educational status, history of still birth, number of children to practice of birth preparedness and complication readiness.

\section{Discussion}

The study results showed that $236(65.6 \%)$ of the respondents were aware of birth preparedness and complication readiness, this results is similar to the 655 $(70.6 \%)$ from a study carried out in southeastern Nigeria on Awareness of birth preparedness and complication readiness [18]. This could be because; most of the respondents in both studies were educated and informed.

The results obtained in this study show a lower value, compared with $546(87.4 \%)$ in a study done Edo State Nigeria on the assessment of birth preparedness and complication readiness [19]. The reason for this disparity could be due to the fact that most of the respondents in the study done in Edo state were more aware of the components of birth preparedness and complication readiness and hence seem to be more knowledgeable.

In this study, the two key danger signs during pregnancy which were spontaneously mentioned by the respondents were severe vaginal bleeding $312(86.7 \%)$ and convulsion 291 (80.8 \%). During labour the danger signs mostly mentioned by the respondents were severe vaginal bleeding bleeding $269(74.7 \%)$ and severe headache 229 $(63.6 \%)$, this is high when compared results form a study done in Jimma Ethiopia, were severe vaginal bleeding 212 $(49.5 \%)$ and convulsion $120(16.3 \%)$ were mentioned spontaneously as danger signs during labour and childbirth [8]. This difference maybe because the Jimma Ethiopia is a rural area and as such the respondents are likely to be less exposed and illiterate.

In this study only $16(4.4 \%)$ of respondents had knowledge of financial support systems provided in the community. Community resources were poorly known or recognized by the majority of women, which corroborates with earlier studies in Abia, Nigeria and contrary to what was reported in West Bengal [12, 20]. This could be due to the fact that these studies were unavailable or because information about them was not made available to the mothers. The approach to tackling this problem is to involve and obtain the commitment of local government chairpersons, local community, and opinion leaders, with the aim of strengthen the existing service; so as to be able to provide local transport, blood donors and emergency funds through community health funds. The local media, grass-root faith-based organizations, and nongovernmental agencies can be involved to carry out information dissemination as well.

In this study, $271(75.3 \%)$ of the respondents had a positive attitude towards birth preparedness and complication readiness. This is in contrast to a study done in India where $453(53.3 \%)$ of the respondents showed a favorable attitude to birth preparedness and complication readiness. This disparity could be because the respondents in the study done in India were less educated and as such will likely show a negative attitude to birth preparedness and complication readiness [21].

The overall result of birth preparedness and complication readiness index was graded as prepared for birth and its complications and not prepared for birth and its complications. In this study, $124(34.4 \%)$ of the respondents were prepared for birth and its complications. This is incontrast to a study done in Indore, India, where $321(47.8 \%)$ of the respondents were well-prepared for birth and its complications [22]. In a community based cross-sectional study done in Chamwino district,in Tanzania, 234 (58.2\%) of the respondents were considered as prepared for birth [16].There is also similarity seen in a study done in Mbarara district Uganda where 128 (35\%) of the respondents were well prepared [5].

In this study, factors associated with birth preparedness and complication readiness are: level of education $(\mathrm{p}=0.0001)$, history of still birth $(\mathrm{p}=0.0001)$, and Parity $(\mathrm{p}=0.0001)$ which emerged as the predictors of the respondents' readiness for complications. This finding agrees with that of Hiluf and Fantahun from Ethiopia, where preparation for birth and its complication was found higher among literate mothers, women with parity range of 2 to 4 , women with history of stillbirth, and those who were advised about birth preparedness during their antenatal care follow-up [13].

\section{Conclusions}

Generally, a number of 229 (63.6\%) of the respondents in this study, have a good knowledge of birth preparedness and complication readiness components. This study showed that the number respondents $271(75.3 \%)$ had a positive attitude to birth preparedness and complication readiness components. The practice of birth preparedness and complication readiness components at 12 4(34. 4\%) shows that despite the respondents good knowledge and positive attitude, they still do not practice birth preparedness and complication readiness. This study revealed that the proportion of pregnant women who prepared for birth and were ready for its complications was not satisfactory. Repeated awareness programs should be initiated at the Primary Health Care centers towards community participation so that Birth Preparedness and Complication Readiness status improves for these women. This will be a positive step toward achieving the millennium development goal 5, of safe motherhood and reduction in maternal mortality. Birth preparedness and complication readiness, as components of focus antenatal care are an important concept that will significantly reverse the current trend of maternal morbidity and mortality 
experienced in our community if strictly followed. Birth preparedness and complication readiness involves not only the pregnant woman, but also her family, community, and the available health care providers. Therefore, they need to collaborative in their efforts to support this group of people, for a robust, effective and efficient health care delivery. Therefore, to reduce the economic implications as a result of maternal death in Nigeria, health and policy stakeholders, together with the community must take adequate steps to ensure early education among the girls at young age, providing adequate blood bank services and engaging in constant researches in the field of birth preparedness and complication readiness.

\section{Acknowledgements}

My profound thanks and gratitude goes to the Almighty God who in his infinite mercy and guidance saw me through this training programme.

I wish to express my sincere thanks and appreciation to my supervisor Prof. A. T Onajole for his diligent direction, constructive criticism, suggestion, corrections and final approval.

My special appreciation goes to Dr Ayela, for granting me the approval to embark on data collection. I am greatly indebted to Mrs Ann Oru for her assistance in aspects of data management. I wish to appreciate my research assistants for their very useful services in the Conduct of this research. I will not fail to thank all the pregnant women who participated in the project, for their understanding, patience and cooperation throughout the period of the research. My sincere appreciation goes to my lovely parents Sir and Lady S.C Metu and my siblings Chisom, Muanya, Oby, Goodluck, Esther and Amara for their support and prayers.

Finally, I acknowledge with much pleasure the kind cooperation, endurance, understanding and support of my husband Prince Fred Mbonu and my children: Stephanie, Jennifer and Jessica. May the Almighty God bless, guide and protect you all abundantly for your different contributions towards the successful completion of this project.

\section{REFERENCES}

[1] Adogu POU, Njelita IA, Ilika AL. Birth preparedness and emergency readiness of pregnant women in Amaku general hospital Awka, Nigeria. Trop J Med Res. 2013 Jul $22 ; 16(2): 42-5$

[2] John Hopkins Program for International Education in Gynecology and Obstetrics (JHPIEGO). Birth Preparedness and Complication readiness: A Matrix of Shared Responsibilities. Maternal and Neonatal Program. Baltimore 2001. Available at:http://www.jhpiego.org./files
/bpcrmatrix.pdf(Accessed 02 August 2015).

[3] World Health Organization. Managing complications in pregnancy and childbirth .World Health Organization. 2012.Available

at:http://www.who.int/reproductivehealth/publications/mat ernal perinatal health/924 1545879/en.(Accessed 02 August 2015)

[4] Solnes Miltenburg A, Roggeveen Y, Van Elteren M, Shields L, Bunders J, van Roosmalen J, et al. A protocol for a systematic review of birth preparedness and complication readiness programs. Syst Rev. 2013 Feb 8; 2:11.

[5] Urassa DP, Pembe AB, Mganga F. Birth preparedness and complication readiness among women in Mpwapwa district, Tanzania. Tanzan J Health Res. 2012 Jan 10; 14:1.

[6] World Health Organization. Maternal health .2012. World Health Organization. Available from:

http://www.who.int/topics/maternal_health/en/.(Accessed 02 August 2015)

[7] National Population Commission of Nigeria.Census and Statistics .2013. Available from:

http://www.population.gov.ng/(Accessed 02 August 2015).

[8] United Nations Children Fund. The State of the World's children.Maternal and Newborn Health.2009. Available at: http://www.unicef.org/state of the world children/health /en/. (Accessed 02 August 2015).

[9] Islam M. The Safe Motherhood Initiative and beyond. Bull World Health Organ. 2007 Oct; 85(10):735.

[10] Martines J, Paul VK, Bhutta ZA, Koblinsky M, Soucat A, Walker N, et al. Neonatal survival: a call for action. Lancet Lond Engl. 2005 Apr 26; 365(9465):1189-97.

[11] United Nations Population Funds.State of World Population .2013 Available from:

http://www.unfpa.org/publications/state-world-population2013. (Accessed 02 August 2015).

[12] Mukhopadhyay D, Mukhopadhyay S, Nayak S, Biswas A, Biswas A, Bhattacharjee S. Status of birth preparedness and complication readiness in Uttar Dinajpur District, West Bengal. Indian J Public Health. 2013;57(3):147.

[13] Hiluf M, Fantahun M. Birth preparedness and complication readiness among women in Adigrat town, north Ethiopia. Ethiop J Health Dev. 2008 Aug 27; 22(1):14-20.

[14] Margaret Olabisi Araoye. Research Methodology with Statistics for Health and Social Sciences. In: Research Methodology with Statistics for Health and Social Sciences. Nathadex Publishers; p. 118.

[15] JHPIEGO.Monitoring Birth Preparedness and Complication Readiness: Tools and Indicators for Maternal and Newborn Health.2005.Available from: http://www.jhp iego.org/files/BPCRtoolkit.pdf(Accessed 02 August 2015).

[16] Bintabara D, Mohamed MA, Mghamba J, Wasswa P, Mpembeni RNM. Birth preparedness and complication readiness among recently delivered women in chamwino district, central Tanzania: a cross sectional study. Reprod Health. 2015; 12:44.

[17] Kaso M, Addisse M. Birth preparedness and complication readiness in Robe Woreda, Arsi Zone, Oromia Region, 
Central Ethiopia: a cross-sectional study. Reprod Health. 2014; 11: 55.

[18] Ekabua JE, Ekabua KJ, Odusolu P, Agan TU, Iklaki CU, Etokidem AJ. Awareness of Birth Preparedness and Complication Readiness in Southeastern Nigeria. ISRN Obstet Gynecol .2011; 4: 15 .

[19] Ofili A, OkojieO. Assessment of the role of traditional birth attendants in maternal health care in Oredo Local Government Area, Edo State, Nigeria. Journal of Community Medicine and Primary Health Care. 2005; 17(1): 55-60.

[20] Emma-Ukaegbu UC, Nwokeukwu HI, Uzochukwu BSC.
An Assessment of Birth Preparedness and Complication Readiness in Antenatal Women In Umuahia North Local Government Area, Abia State, Nigeria. Age. 2014; 20: 20 4.

[21] Kabakyenga JK, Östergren P-O, Turyakira E, Pettersson KO. Influence of Birth Preparedness, Decision-Making on Location of Birth and Assistance by Skilled BirthAttendants among Women in South-Western Uganda. PLoS ONE. 2012 Apr 27; 7 (4):e35747.

[22] Agarwal S, Sethi V, Srivastava K, Jha PK, Baqui AH. Birth Preparedness and Complication Readiness among Slum Women in Indore City, India. J Health Popul Nutr. 2010 Aug;28 (4):383-91. 